\title{
CRYSTAL \\ Hierarchical DL-Glutamic Acid Microspheres from Polymer-Induced Liquid Precursors
}

\author{
Yuan Jiang, ${ }^{+, \|}$Laurie Gower, $^{\neq}$Dirk Volkmer, $^{\S}$ and Helmut Cölfen ${ }^{*,+, \|}$ \\ ${ }^{\dagger}$ Max Planck Institute of Colloids and Interfaces, Colloid Chemistry, Am Mühlenberg, D-14476 Golm, Germany \\ ${ }^{\ddagger}$ Materials Science \& Engineering, University of Florida, Gainesville, Florida 32611, United States \\ ${ }^{\S}$ Institute of Physics, Chair of Solid State \& Materials Chemistry, Augsburg University, D-86159 Augsburg, Germany
}

Supporting Information

ABSTRACT: Nanostructured organic crystals have a broad application potential as pharmaceuticals, pigments, or catalysts. The development of facile and reproducible synthetic routes and the upscaling of the process, however, still remain a challenge. Here, we describe the synthesis of macroporous

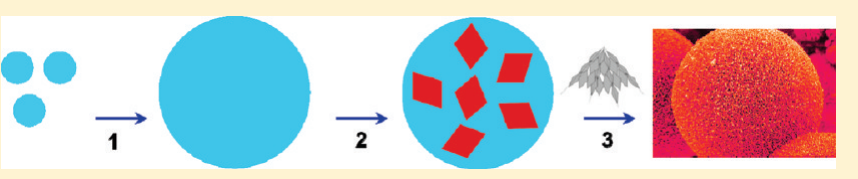
hierarchically structured microspheres with nanoplatelets as building blocks of a model organic molecule-DL-glutamic acid (DL-Glu) — via a polymer-induced liquid precursor (PILP) phase using oppositely charged polyethylene imine (PEI) as a polymeric additive. The impacts of experimental parameters such as [DL-Glu], temperature, solvent composition, and the $\mathrm{pH}$ value were systematically investigated for the DL-Glu morphosynthesis process. A mechanism is suggested to explain the precipitation of DL-Glu with PEI as an additive based on a multistep process: (1) the formation, growth, and coalescence of the PILP droplets; (2) the homogeneous nucleation of nanoplatelets within PILP droplets and (3) the reorientation of nanoplatelets into hierarchical microspheres. This model system can be further extended to the precipitation of other amino acids that have a net charge opposite to that of the polyelectrolyte additive.

\section{INTRODUCTION}

Biominerals are hierarchical structures with nanostructured building blocks. ${ }^{1}$ A variety of inorganic materials have been applied as model systems to investigate the mechanism of biomineralization and bioinspired crystallization. ${ }^{2-4}$ Crystallization of organics can also be suitable as a model system to understand the basic principles of crystallization control starting from the molecular scale. Organic crystals have lower lattice energy compared to inorganic crystals and exhibit a larger variety of possibilities for molecular recognition, such as chirality or dipole-dipole interactions, because the building blocks for organics are large molecules instead of small ions, as in inorganic counterparts. Therefore, organics can be better influenced by additives. ${ }^{5}$ The ultimate goal of crystallization of organics is the rational design of organic crystals with controllable size, morphology, orientation, polymorph, texture, etc., in an easy and upscalable way.

The Nakanishi group pioneered the reprecipitation method for the preparation of organic nanoparticle dispersions. ${ }^{6}$ The precipitation occurs by adding a miscible nonsolvent into the mother liquor. The high supersaturation immediately induces a complex nucleation process, and the following growth process always passes through a nanoparticle dispersion state. ${ }^{7}$ Although some as-prepared nanoparticle dispersions lacking stabilizer can be stable for a long period of time, most of them are unstable and bulk crystals are obtained from an Ostwald ripening process. Stabilizers such as surfactants, ${ }^{8,9}$ polyelectrolytes, ${ }^{10-12}$ dendrimers, ${ }^{13}$ double hydrophilic block copolymers, ${ }^{14-17}$ and surfactant-polyelectrolyte mixtures ${ }^{18-21}$ are usually added to at least temporarily stabilize nanoparticles from recrystallization in dispersions. Even with stabilizers, as-prepared nanoparticles do not exist as isolated particles in many cases. Instead, they selfassemble into hierarchical superstructures. The coupling of nanoparticle formation and subsequent controllable assembly or organization can be considered as one type of nonclassical crystallization., ${ }^{4,22,23}$ The aggregation of nanoparticles can also pass through a fast self-organization process, resulting in complex superstructures with nanoparticle building blocks. ${ }^{24}$

Until now, a general and simple method is missing for the construction of nanoparticle superstructures and for shaping such structures into a desirable morphology at the micro- and macroscale. A promising method for generating complex structures is to form either liquid or amorphous precursors. For example, an amorphous precursor with fluidic character can be generated by the so-called "polymer-induced liquid-precursor" (PILP) process. This synthesis route was put forward by Gower for the crystallization of $\mathrm{CaCO}_{3}$ in the presence of $\mu \mathrm{g} \cdot \mathrm{mL}^{-1}$ amounts of a polyacid (e.g., polyacrylic or polyaspartic acid). ${ }^{25-27}$ The advantage of the PILP route is that a PILP phase can transform into crystals with complex shapes if the shape of the precursor is retained upon crystallization (i.e., by a pseudomorphic transformation). ${ }^{25,27}$ The Cölfen group extended the PILP approach to the precipitation of

\footnotetext{
Received: April 20, 2011

Revised: $\quad$ May 26, 2011

Published: June 13, 2011
} 
organics such as amino acids ${ }^{11}$ and organic pigments ${ }^{15}$ by using oppositely charged polyelectrolytes or copolymers with matching chemical patterns as additives; however, the level of structural variation was not investigated until now in how far these structures could be varied $^{16,28}$

Herein, we provide a systematic investigation for the preparation of DL-glutamic acid (DL-Glu) macroporous microspheres with branched polyethyleneimine (PEI) as an additive to promote the PILP route of crystallization. The experiments were performed by mixing DL-Glu-PEI aqueous solution with an alcohol, which is a nonsolvent to DL-Glu. A series of parameters, such as the concentrations of DL-Glu and PEI, the alcohol/ aqueous solution volume ratio, temperature, the $\mathrm{pH}$ value, and the type of alcohol were tuned to optimize the procedure for the preparation of pure microspheres. Finally, the method was extended to the preparation of chiral amino acid microspheres.

\section{EXPERIMENTAL SECTION}

DL-Glutamic acid monohydrate, L-lysine $\cdot \mathrm{HCl}(\mathrm{L}-\mathrm{Lys} \cdot \mathrm{HCl})$, L-histindine (L-His), L-glutamic acid (L-Glu), D-glutamic acid (D-Glu), $\mathrm{NaOH}$ solid, 95-97 wt $\% \mathrm{H}_{2} \mathrm{SO}_{4}$, and polyethylenimine (PEI) with various average $M_{\mathrm{w}}$ values of $800,1300,2000$, or $750000 \mathrm{~g} \cdot \mathrm{mol}^{-1}$ were obtained from Aldrich. Poly(acrylic acid) (PAA; 63 wt \% aqueous solution; average $M_{\mathrm{W}}=\sim 2000 \mathrm{~g} \cdot \mathrm{mol}^{-1}$; acrylic resin $47 \mathrm{wt} \%$, sodium polyacrylate 16 wt $\%$, water 37 wt \%; $\mathrm{pH}=2.2-3.0$ ) was purchased from Acros Organics. Double distilled water was used for the preparation of samples in aqueous solutions. Ethanol, methanol, isopropanol, and $n$ propanol were obtained from Merck. All chemicals were used directly without any further purification.

A series of aqueous solutions containing a quantity of DL-Glu (L-Glu or D-Glu) and PEI was prepared at $60{ }^{\circ} \mathrm{C}$ or RT. The solvent was pure water, $1 \mathrm{M} \mathrm{NaOH}$ aqueous solution, or $0.5 \mathrm{M} \mathrm{H}_{2} \mathrm{SO}_{4}$ aqueous solution. The above aqueous solution was stirred for $24 \mathrm{~h}$ before it was quickly charged into alcoholic solution at various volume ratios by using a micropipet. After being shaken by hand for a few seconds, the mixture was then kept quiescent for $48 \mathrm{~h}$ at RT for the completion of precipitation. Finally, the precipitates were rinsed with ethanol three times to remove the unbound PEI completely. A series of aqueous solutions containing a quantity of $\mathrm{L}-\mathrm{His}(\mathrm{L}-\mathrm{Lys} \cdot \mathrm{HCl})$ and PAA was prepared with water as solvent at RT. The following steps were the same as in the DL-Glu precipitation procedure.

Optical microscopy images were taken with a Leica DMRB microscope. SEM and TEM measurements were performed on an LEO 1550 GEMINI and EM 912 Omega, respectively. X-ray diffractograms were recorded on a Bruker D8 advance diffractometer. Nitrogen sorption measurements were performed at $77 \mathrm{~K}$ using a Quadrasorb instrument from Quantachrome Instruments. The turbidity measurement was performed with a UV-vis spectrophotometer (Varian Cary 50) with a light wavelength $500 \mathrm{~nm}$.

\section{RESULTS}

Parameter Optimization for Obtaining Pure Microspheres. It is known that DL-Glu precipitates directly into sheetlike structures if the mother liquor is mixed with ethanol $(\mathrm{EtOH}){ }^{29}$ However, adding PEI (branched, average $M_{\mathrm{w}}=800 \mathrm{~g} \cdot \mathrm{mol}^{-1}$ ) to an aqueous solution of DL-Glu induces a complex phase behavior of the quaternary DL-Glu/PEI/water/EtOH system. ${ }^{30}$ With the reaction parameters shown in Figure 1A, the precipitation of DL-Glu usually resulted in two morphologies: single crystalline sheets and microspheres (Figure 1A). As microspheres were the only product attributed to the PILP route, ${ }^{11}$ various parameters
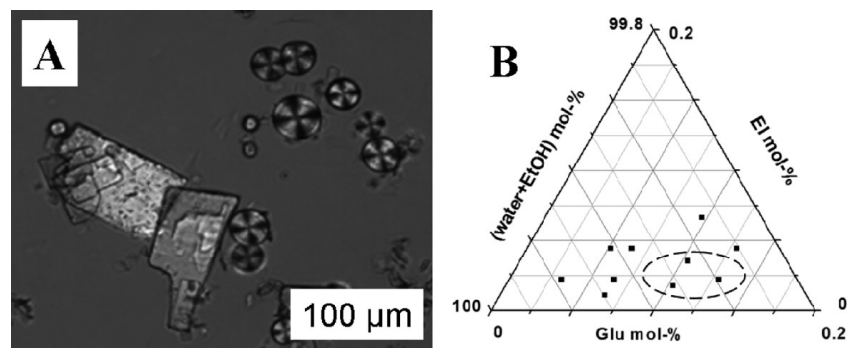

Figure 1. (A) Representative image showing the coexistence of single crystalline sheets and microspheres $\left([\mathrm{DL}-\mathrm{Glu}]=0.14 \mathrm{~mol} \cdot \mathrm{L}^{-1},[\mathrm{EI}]=\right.$ $\left.0.03 \mathrm{~mol} \cdot \mathrm{L}^{-1}, V_{\mathrm{Et}} / V_{\mathrm{Aq}}=9, \mathrm{pH}=3.6, \mathrm{RT}\right)$. (B) Ternary phase diagram indicating the composition of the quaternary system $\left(V_{\mathrm{Et}} / V_{\mathrm{Aq}}=9, \mathrm{pH}=\right.$ 3.6, $60^{\circ} \mathrm{C}$; the molar concentrations of water and $\mathrm{EtOH}$ were combined into one axis because $V_{\mathrm{Et}} / V_{\mathrm{Aq}}$ was constant). The compositions which result in the formation of pure microspheres are circled.

have been investigated to optimize the procedure for the selective preparation of pure microspheres (Figure 1B). The standard system investigated is a quaternary (DL-Glu)/PEI/water/EtOH (methanol, isopropanol, or $n$-propanol) system. The influence of important parameters such as [DL-Glu], [EI] (we use the concentration of the repeating structural unit ethylene imine (EI) instead of PEI for a better understanding of the molar ratios between DL-Glu and PEI additive), $\mathrm{pH}$ value, the volume ratio of EtOH and DL-Glu-PEI aqueous solution $\left(V_{\mathrm{Et}} / V_{\mathrm{Aq}}\right)$, and temperature will be discussed in the following paragraphs.

The effect of the solute composition was investigated first. A series of experiments was performed by mixing DL-Glu-PEI aqueous solution with $\mathrm{EtOH}$ at $60{ }^{\circ} \mathrm{C}\left(V_{\mathrm{Et}} / V_{\mathrm{Aq}}=9, \mathrm{pH}=3.6\right)$. Afterward, the reaction system was cooled down to RT and remained to react at RT for at least $24 \mathrm{~h}$. The compositions of the quaternary mixtures investigated are summarized in Figure 1B. Pure microspheres were prepared when the value of the [DL-Glu $] /[\mathrm{EI}]$ molar ratio was between $2.5 / 1$ and $5 / 1$ and by using nearly saturated or supersaturated Glu-PEI aqueous solutions; otherwise, a mixture of microspheres and single crystalline sheets was obtained. In addition, increasing the solubility of DLGlu by increasing the temperature to $60{ }^{\circ} \mathrm{C}$ was also an advantageous factor for the preparation of microspheres in large quantities. Indeed, only a mixture of single crystalline sheets and microspheres was obtained when the mixing procedure was performed at RT.

Altering the $\mathrm{pH}$ of the DL-Glu-PEI solution to a value of 0.5 also increased the DL-Glu solubility, which was even more effective for the production of microspheres than the temperature increase. The results are summarized in Tables $s 1$ and s2. Switching the $\mathrm{pH}$ value to the basic range ( 13 for example) could also increase the solubility of DL-Glu. However, only single crystalline sheets were obtained under this condition because this $\mathrm{pH}$ was above the $\mathrm{p} K_{\mathrm{a}}$ value of PEI $\left(\mathrm{p} K_{\mathrm{a}}=10.2\right)$, which is no longer protonated under these conditions.

The polarity of the solvent in the quaternary mixtures is a key parameter for controlling the driving force of precipitation. It can be tuned by changing the length of the alkane groups of the alcohol as well as the volume ratio of alcohol and DL-Glu-PEI aqueous solution. First, if isopropanol and $n$-propanol were used for the preparation of microspheres, only single crystalline sheets were obtained $\left([\mathrm{DL}-\mathrm{Glu}]=0.14 \mathrm{~mol} \cdot \mathrm{L}^{-1},[\mathrm{EI}]=0.05 \mathrm{~mol} \cdot \mathrm{L}^{-1}\right.$, $\left.V_{\text {alcohol }} / V_{\text {aq }}=9, \mathrm{pH}=3.6,60^{\circ} \mathrm{C}\right)$. Both alcohols are more hydrophobic as compared to $\mathrm{EtOH}$, due to their longer alkane 

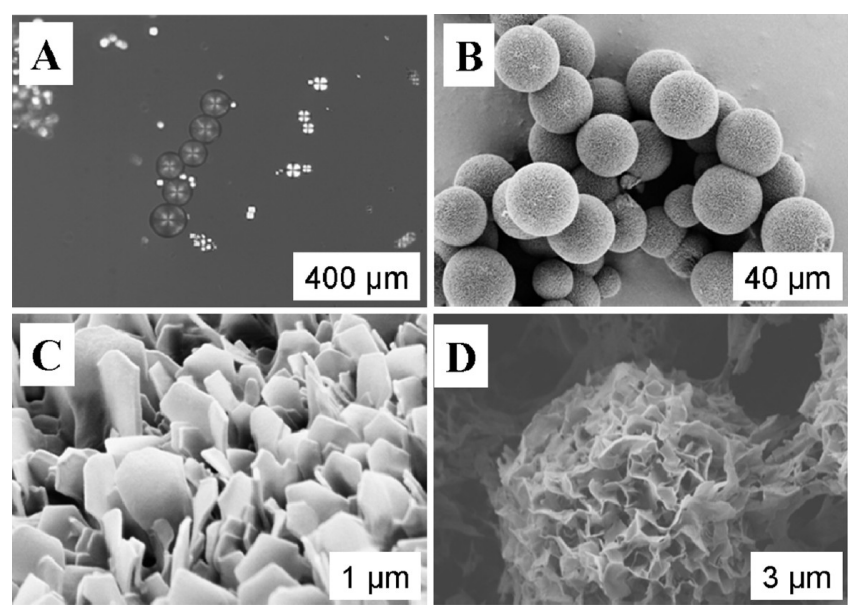

Figure 2. Morphology analysis. Images $A$ and B are POM and SEM images of DL-Glu microspheres, respectively. Image $\mathrm{C}$ is a higher magnification SEM image of a microsphere surface. Reaction conditions: $[\mathrm{DL}-\mathrm{Glu}]=0.2 \mathrm{~mol} \cdot \mathrm{L}^{-1},[\mathrm{EI}]=0.04 \mathrm{~mol} \cdot \mathrm{L}^{-1}, V_{\mathrm{Et}} / V_{\mathrm{Aq}}=9, \mathrm{pH}=3.6,60$ ${ }^{\circ} \mathrm{C}$. Image D is a SEM image of sample 3 in Table s1.

chains. Therefore, both of them can increase the kinetics of direct Glu precipitation instead of the PILP formation. Pure microspheres were obtained by using methanol as a nonsolvent ([DL$\mathrm{Glu}]=0.14 \mathrm{~mol} \cdot \mathrm{L}^{-1},[\mathrm{EI}]=0.05 \mathrm{~mol} \cdot \mathrm{L}^{-1}, V_{\mathrm{MeOH}} / V_{\mathrm{aq}}=9$, $\left.\mathrm{pH}=3.6,60^{\circ} \mathrm{C}\right)$. However, only a small quantity of DL-Glu microspheres was obtained due to the high polarity of methanol. Therefore, the driving force of DL-Glu precipitation in the methanol-water mixture was not as strong as that in the EtOH-water system. Next, various values of $V_{\mathrm{Et}} / V_{\mathrm{aq}}$ at $5,7,9$, and 11 were tested for the preparation of microspheres in the $\mathrm{EtOH}$-water system. Pure microspheres were only obtainable when the values of $V_{\mathrm{Et}} / V_{\mathrm{Aq}}$ were at 11 and 9; otherwise, a mixture of microspheres and single crystalline sheets was obtained. Thus, the mixture at $V_{\mathrm{Et}} / V_{\mathrm{aq}}=9$ was used for the preparation of microspheres thereafter.

Several additional parameters were tested. First, a series of PEI samples with various average $M_{\mathrm{w}}$ values at $800,1300,2000$, and $750000 \mathrm{~g} \cdot \mathrm{mol}^{-1}$ was used for the preparation of microspheres. All as-prepared microspheres were similar in morphology. The result implies that only the charge density of the polyelectrolyte is important rather than the chain length. Our observation is different from that in inorganic crystallization systems, where it was found that the molecular weight of polymeric additives affects the as-prepared crystal morphology. ${ }^{31,32}$ In addition, quiescent conditions, without stirring, were preferential for the preparation of microspheres. In a standard experiment, the quaternary mixture was left quiescent after an initial hand shaking of the reaction vessel for homogeneous mixing. Otherwise, stirring caused the formation of gluelike precipitates that adhered to the vessel wall. Furthermore, complex formation between DL-Glu and PEI in the aqueous solution is the prerequisite for the formation of microspheres. A control experiment was performed by mixing DL-Glu solution with the alcoholic solution of PEI, which resulted in single crystalline sheets.

Morphology and Crystal Structure Analysis. Figure 2A-C provides the structural details of the microspheres. When viewed by polarized optical microscopy (POM), the as-prepared microspheres show a clear Maltese-cross extinction pattern between the crossed polarizers, which suggests the existence of lamellar

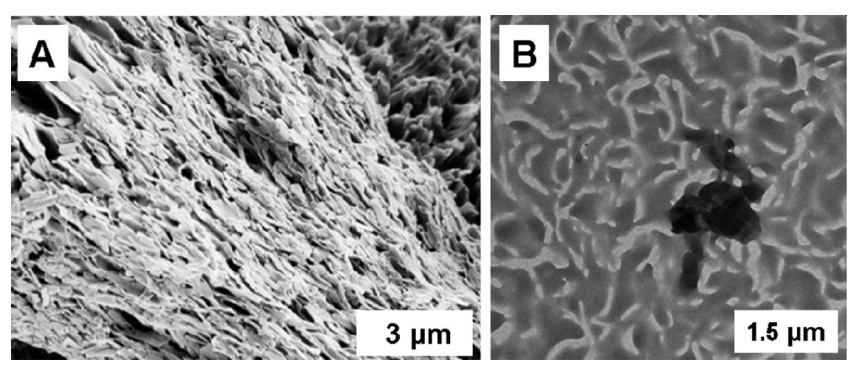

Figure 3. Analysis of internal microstructure. Image A is a SEM image showing the inner structure of a broken microsphere. Image $B$ is a transmission electron microscopy (TEM) image of the same sample prepared by microtome sections of a microsphere roughly perpendicular to the radial direction. Reaction conditions for the preparation of both samples: $[\mathrm{DL}-\mathrm{Glu}]=0.2 \mathrm{~mol} \cdot \mathrm{L}^{-1},[\mathrm{EI}]=0.04 \mathrm{~mol} \cdot \mathrm{L}^{-1}, V_{\mathrm{Et}} / V_{\mathrm{Aq}}=9$, $\mathrm{pH}=3.6,60^{\circ} \mathrm{C}$.
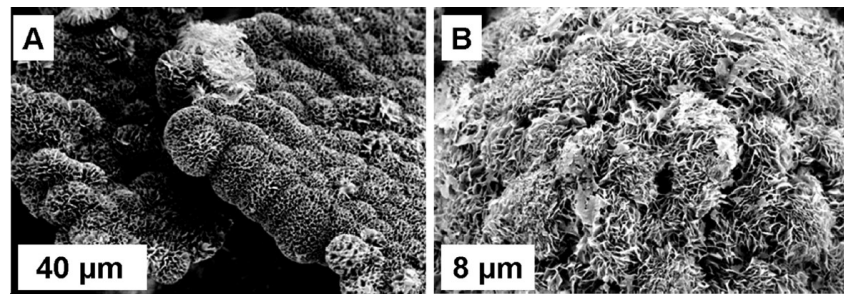

Figure 4. SEM images of superstructures with microspheres as building blocks. The reaction parameters for image A: $[\mathrm{DL}-\mathrm{Glu}]=0.2 \mathrm{~mol} \cdot \mathrm{L}^{-1}$, $[\mathrm{EI}]=0.08 \mathrm{~mol} \cdot \mathrm{L}^{-1}, V_{\mathrm{Et}} / V_{\mathrm{Aq}}=9, \mathrm{pH}=3.6,60^{\circ} \mathrm{C}$. Image $\mathrm{B}$ was taken by using sample 4 in Table s1.

assemblies in a radial orientation (Figure 2A). The microspheres are polydisperse in size, from several micrometers to $\sim 100 \mu \mathrm{m}$ : most of them with sizes between 7 and $20 \mu \mathrm{m}$ (Figure 2B). The magnified image in Figure 2C shows that nanoplatelets of dimensions $200-1000 \mathrm{~nm}$ in width orient themselves in a radial direction toward the microsphere surface. The thickness is $\sim 40 \mathrm{~nm}$, and its distribution is monodisperse from the same image.

DL-Glu microspheres prepared by using DL-Glu-PEI solutions at $\mathrm{pH}=0.5$ show another morphology. Their sizes are between $\sim 2$ and $10 \mu \mathrm{m}$, and the microspheres consist of twisted and continuous nanoplatelets (Figure 2D). In addition, microspheres prepared by using $\mathrm{pH}=0.5$ aqueous solutions show specific surface area as high as $17 \mathrm{~m}^{2} \cdot \mathrm{g}^{-1}$, according to a BET measurement, while those prepared by using a $\mathrm{pH}=3.6$ solution show a significantly lower specific surface area of only $2.5 \mathrm{~m}^{2} \cdot \mathrm{g}^{-1}$.

Two methods have been applied to investigate the inner structure of the microspheres. In the first route, the microspheres were ground into small pieces. Figure $3 \mathrm{~A}$ shows that, in the microspheres, the nanoplatelets are arranged in a radial way. This result corresponds well to the existence of Maltese-cross patterns in POM (Figure 2A), which also suggests the radial orientation of building blocks. Microspheres were also embedded into epoxy resin to obtain microtome cuts. Figure $3 \mathrm{~B}$ proves again that the microspheres have nanoplatelets as building blocks. The thickness of the nanoplatelets is polydisperse from 40 to $100 \mathrm{~nm}$ (Figure 3B). The polydispersity might be due to the cutting procedure, which bent the nanoplatelets. Therefore, the cutting did not go vertical to the surface with the largest surface area of nanoplatelets and enlarged the thickness of a quantity of nanoplatelets. 

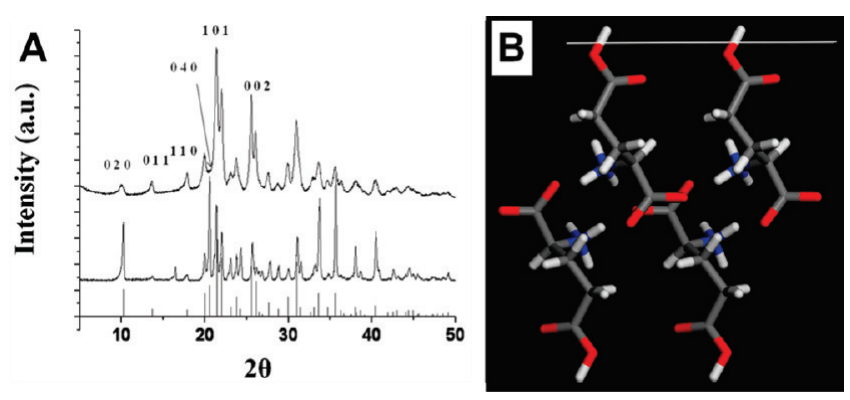

Figure 5. Crystal structure analysis. (A) XRD diffractograms of microspheres (upper) and single crystalline sheets (middle; prepared by mixing saturated DL-Glu aqueous solution with EtOH without PEI additive), and the simulated diffractogram of $\beta$-L-Glu (bottom). Some important peaks are labeled. (B) Side view of the $\left(\begin{array}{lll}0 & 2 & 0\end{array}\right)$ surface of $\beta$ L-Glu (white line). Gray $=$ carbon, red $=$ oxygen, blue $=$ nitrogen $($ from Materials studio 5.5., Accelrys).

In addition to the isolated microspheres, microsphere superstructures were sometimes observed. SEM images show that the sheetlike superstructures are microsphere monolayers, where microspheres are densely packed within the monolayer along the wall of the vessel (Figure 4A). The superstructure could grow as large as centimeters. Some microspheres were merged together (Figure 4A), which suggests that the nucleation of nanoplatelets occurs after partial merging of the PILP droplets. Microspheres prepared by using a $\mathrm{pH}=0.5$ solution could also form superstructures, but as a particle aggregate rather than a monolayer. A microsphere superstructure hundreds of micrometers in diameter is composed of small microspheres $\sim 5 \mu \mathrm{m}$ in size as building blocks (Figure 4B).

The crystal structure of as-prepared microspheres was examined with X-ray diffraction (XRD). The XRD results (Figure 5A) indicate that both the DL-Glu microspheres and the single crystalline sheets from a controlled precipitation experiment without PEI additive show a $\beta$-L-Glu $(\beta$-D-Glu) structure $\left(P 2_{1} 2_{1} 2_{1}, a=5.159, b=17.30, c=6.948, \alpha=\beta=\gamma=90^{\circ}\right){ }^{33}$ Therefore, the microspheres formed conglomerate structures. An orientation effect can be observed when patterns of microspheres and single crystalline sheets are compared (Figure 5A). The intensities of the (lllll $\left.\begin{array}{lll}0 & 0\end{array}\right)$ and $\left(\begin{array}{lll}0 & 4 & 0\end{array}\right)$ peaks in the microspheres are highly decreased. In addition, the (llll $\left.\begin{array}{lll}0 & 0\end{array}\right)$ peak is broadened, and evaluation of the domain size via the Scherrer equation gives a size estimate of $20 \mathrm{~nm}$. To explain these findings, it is necessary to develop a molecular understanding of the interactions between PEI and $\beta$-L-Glu. Calculation of the molecular surface structure of the ( $\left(\begin{array}{lll}0 & 2 & 0\end{array}\right)$ face of $\beta$-L-Glu by using the program Materials studio 5.5 (Accelrys) reveals that this surface can exclusively expose carboxyl groups (Figure 5B). The intensity decrease of the $\left(\begin{array}{lll}0 & 2 & 0\end{array}\right)$ peak in the XRD diffractogram, together with its simultaneous broadening for the microspheres as compared to the single crystalline sheets, is indicative of a decrease of the sample thickness in the [ $\left[\begin{array}{ll}0 & 2\end{array}\right]$ ] direction. This can be explained by electrostatic binding of PEI to the deprotonated carboxyl groups on this surface as well as hydrogen bonding interactions. Both interactions block the growth of crystals along this direction. On the other hand, the ( $\left.\begin{array}{lll}0 & 1 & 1\end{array}\right),\left(\begin{array}{lll}1 & 1 & 0\end{array}\right),\left(\begin{array}{lll}1 & 0 & 1\end{array}\right)$, and $\left(\begin{array}{lll}0 & 0 & 2\end{array}\right)$ peaks increase in intensity (Figure s1). All these faces also expose carboxyl groups-although less than the (ll 2200$)$ facesand therefore will also electrostatically bind the positively charged PEI at $\mathrm{pH} 3.6$ as well as via hydrogen bridges. This

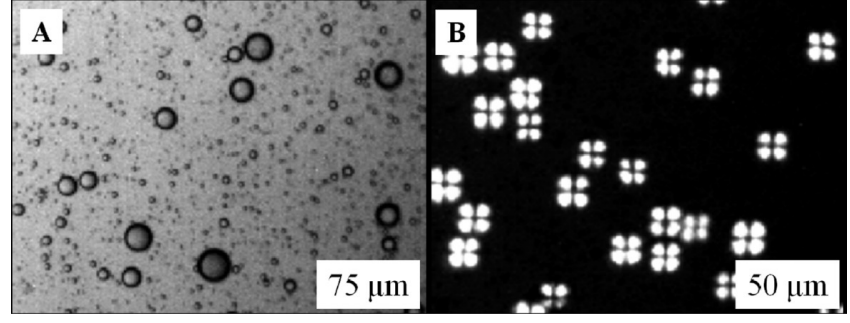

Figure 6. Stages of the reaction. (A) OM image showing the existence of PILP droplets after reaction for $10 \mathrm{~min}$. (B) POM picture showing the existence of DL-Glu microspheres adhered on the upper wall of the quartz cuvette after reaction for $1 \mathrm{~h}$. [DL-Glu] $=0.2 \mathrm{~mol} \cdot \mathrm{L}^{-1},[\mathrm{EI}]=0.04$ $\mathrm{mol} \cdot \mathrm{L}^{-1}, V_{\mathrm{Et}} / V_{\mathrm{Aq}}=9, \mathrm{pH}=3.6,60^{\circ} \mathrm{C}$. The observation was performed directly within a closed quartz cuvette at RT.

means that the crystal is longer in the $\left[\begin{array}{lll}0 & 1 & 1\end{array}\right],\left[\begin{array}{lll}1 & 1 & 0\end{array}\right],\left[\begin{array}{lll}1 & 0 & 1\end{array}\right]$, and $\left[\begin{array}{lll}0 & 0 & 2\end{array}\right]$ directions as compared to the $\left[\begin{array}{lll}0 & 2 & 0\end{array}\right]$ directions.

The vacuum morphologies of the nanoplatelets in the microspheres and single crystalline sheets were also calculated with the software Cerius $^{2}$ (Accelrys) (Figure s2). The face with the largest area in both structures is the (lllll $\left.\begin{array}{ll}0 & 0\end{array}\right)$ face. In addition, the $\left(\begin{array}{lll}0 & 0 & 2\end{array}\right)$ and $\left(\begin{array}{lll}1 & 0 & 1\end{array}\right)$ faces become newly exposed while the $\left(\begin{array}{lll}1 & 1 & 0\end{array}\right)$ and ( $\left.\begin{array}{lll}0 & 1 & 1\end{array}\right)$ faces have reduced areas in the nanoplatelets as compared to single crystalline sheets.

Investigation of Reaction Mechanism. An in situ experiment was performed to clarify the mechanism of the precipitation of DL-Glu microspheres. An important question is whether the nanoplatelets homogeneously nucleate from PILP droplets or whether they are formed in the solution phase, followed by their self-organization into microspheres. An OM image in Figure 6A indicates the existence of PILP droplets adhered onto the quartz slide after $10 \mathrm{~min}$. The PILP droplets were polydisperse in size, and the larger ones were $\sim 20 \mu \mathrm{m}$ in diameter. The emergence of Maltese-cross-polarization patterns was observed by POM after $\sim 1 \mathrm{~h}$, which is indicative of crystallization to microspheres with radially orientated nanoplatelets formed within each PILP droplet.

The precipitation kinetics of the microspheres from their PILP precursor was monitored by turbidity measurements, as shown in Figure s3. The turbidity decreased with time. The decrease between 0 and $0.5 \mathrm{~h}$ is due to the coalescence and growth of PILP droplets. The following fast decrease between 0.5 and $2.5 \mathrm{~h}$ is attributed to the precipitation of microspheres. After $4 \mathrm{~h}$ of reaction, the reaction mixture was nearly clear due to microsphere sedimentation. The remaining PEI was soluble in the water-EtOH mixture. In combination with the OM observation in Figure 6A, we could not completely separate the turbidity drop caused by the settling of PILP droplets to the bottom from that caused by those adhering to the wall.

Microspheres from Chiral Amino Acids. As DL-Glu microspheres show a conglomerate structure, the synthesis recipe was extended for the preparation of separate L- and D-Glu microspheres, which are shown in Figure 7A and B, respectively. The microspheres are between 10 and $20 \mu \mathrm{m}$ in size, and all nanoplatelets show the same radial orientation as that seen in the DL-Glu microspheres. Therefore, L-Glu and D-Glu microspheres show identical overall spherulitic morphologies, as expected, but with variable platelet size and packing density. Furthermore, a similar procedure has been extended for the preparation of charged amino acid microspheres, such as L-His and $\mathrm{L}$-Lys $\cdot \mathrm{HCl}$, with the oppositely charged poly(acrylic acid) as the additive (Figure $7 \mathrm{C}$ and $\mathrm{D}$ ). 

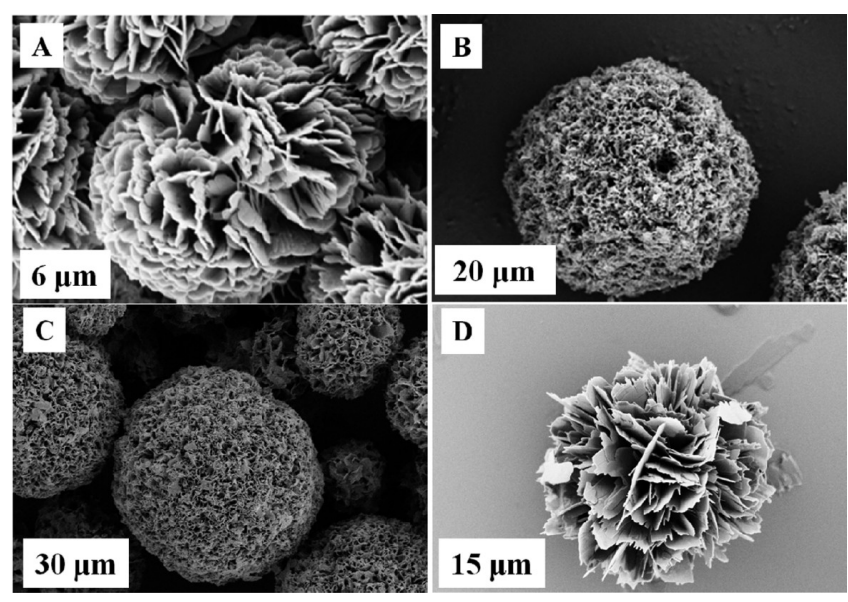

Figure 7. Microspheres from other chiral amino acids. A-D are SEM images of L-Glu, D-Glu, L-His, and L-Lys $\cdot \mathrm{HCl}$ microspheres, respectively. Parameters for A and B: $[\mathrm{D}-$ or L-Glu $]=0.2 \mathrm{~mol} \cdot \mathrm{L}^{-1},[\mathrm{EI}]=0.04$ $\mathrm{mol} \cdot \mathrm{L}^{-1}, V_{\mathrm{Et}} / V_{\mathrm{Aq}}=9, \mathrm{pH}=3.6,60^{\circ} \mathrm{C}$. Parameters for $\mathrm{C}:[\mathrm{L}-\mathrm{His}]=0.52$ $\mathrm{mol} \cdot \mathrm{L}^{-1},[\mathrm{AA}]=0.19 \mathrm{~mol} \cdot \mathrm{L}^{-1}(\mathrm{AA}$ is the abbreviation of acrylic acid, the repeating structural unit of poly(acrylic acid)), $V_{\mathrm{Et}} / V_{\mathrm{Aq}}=7, \mathrm{pH}=$ 5.5, RT. Parameters for D: [L-Lys $\cdot \mathrm{HCl}]=1.4 \mathrm{~mol} \cdot \mathrm{L}^{-1},[\mathrm{AA}]=0.42$ $\mathrm{mol} \cdot \mathrm{L}^{-1}, V_{\mathrm{Et}} / V_{\mathrm{Aq}}=7, \mathrm{pH}=3.6, \mathrm{RT}$.

\section{DISCUSSION}

Amino acids are zwitterions, and altering the $\mathrm{pH}$ value of their aqueous solution is an important way to change their solubilities and to produce various polymorphs and morphologies. ${ }^{14,34}$ Herein, the $\mathrm{pH}$ value is also a key parameter for controlling the interactions between DL-Glu and PEI in the DL-Glu-PEI aqueous solution. The $\mathrm{pH}$ values of $\mathrm{DL}-\mathrm{Glu}-\mathrm{PEI}$ aqueous solutions with water and with $0.5 \mathrm{M} \mathrm{H}_{2} \mathrm{SO}_{4}$ as solvents are 3.6 and 0.5 , respectively. Since the $\mathrm{p} K_{\mathrm{a}}$ values of the two carboxyl groups are 2.19 and 4.25 , in the first case, one carboxyl group is protonated, while in the latter case both are protonated. PEI, on the other hand, has a $\mathrm{p} K_{\mathrm{a}}$ value of $\sim 10$ and is fully protonated under the given conditions. Therefore, DL-Glu and PEI can interact with each other via electrostatic interactions at $\mathrm{pH}$ 3.6. This is no longer possible at $\mathrm{pH} 0.5$; nevertheless, the microspheres still formed, which indicates some type of DL-Glu-PEI interaction. The reason for this is because of the hydrogen bonds which can still occur when in the protonated state. On the other hand, only single crystalline sheets were obtained when the $\mathrm{pH}$ value of the Glu-PEI aqueous solution was 13 . In this case, all primary and secondary amine groups were deprotonated. Therefore, neither electrostatic interaction nor hydrogen bonding was possible between Glu and PEI.

In the precipitation reaction, the molar ratio of [DL-Glu]/[EI] is the key parameter for the preparation of microspheres. There were two precipitation reactions observed in parallel: the one via the PILP phase and the other directly from the bulk mixture. In the $\mathrm{pH}=3.6$ series, pure microspheres were prepared via the PILP route in a range of molar ratios of $[\mathrm{DL}-\mathrm{Glu}] /[\mathrm{EI}]$ between $\sim 2.5$ and $\sim 5$ (Figure $2 \mathrm{~B}$ ). When the molar ratio of [DL-Glu]/ [EI] was lower than 2.5, the driving force for precipitation was not strong because a certain amount of DL-Glu molecules could be trapped in DL-Glu-PEI complexes and kept from being precipitated. On the other hand, in the case where the molar ratio of $[\mathrm{DL}-\mathrm{Glu}] /[\mathrm{EI}]$ was higher than $\sim 5$, not enough DL-Glu could interact with PEI, resulting in the precipitation of single

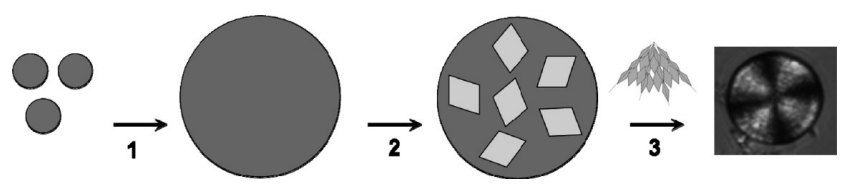

Figure 8. Scenario of a multistep DL-Glu precipitation with PEI as an additive. Step 1 is the formation of PILP droplets and their coalescence; step 2 is the nucleation of nanoplatelets within the PILP droplets; step 3 is the radial growth and organization of the nanoplatelets. Each PILP droplet ranges from several to tens of micrometers in size.

crystalline sheets. Therefore, the molar ratio of $[\mathrm{DL}-\mathrm{Glu}] /[\mathrm{EI}]$ needs to be controlled precisely to ensure that all nucleation events take place within PILP droplets. In addition, using supersaturated DL-Glu aqueous solution was beneficial for the precipitation via the PILP route, resulting in a large amount of microspheres.

The PILP route changes the kinetics of DL-Glu precipitation from a single to a multistep process (Figure 8). Such multistep crystallization processes were theoretically predicted by Frenkel ${ }^{35}$ and experimentally observed for protein crystals ${ }^{36}$ and mineral crystals. ${ }^{37}$ However, it is important to note that the liquid precursors in our phase were formed in the presence of a countercharged polymer and do not originate purely from the crystallizing component. The first step is the coalescence of PILP droplets, which takes $\sim 0.5 \mathrm{~h}$. The subsequent crystallization of the nanoplatelets within each PILP droplet is homogeneous and fast. Most of the PEI is excluded from the microspheres and enters the bulk phase with time. ${ }^{11,38}$ A big benefit of the multistep precipitation via the PILP route is that the nucleation barrier is highly reduced. $35,36,39,40$

Finally, the nanoplatelets orient radially due to space constraints caused by their elongated structure, as well as alignment of dipoles of the dipolar amino acid. A similar dipolar driving force has been observed in the crystallization of alanine mesocrystals. ${ }^{28}$ In this well studied case, continuous crystallization without polymeric additives resulted in mesocrystals followed by the recrystallization into single crystalline structures. In our case, the adsorption of PEI predominantly on the $\left(\begin{array}{lll}0 & 2 & 0\end{array}\right)$ face protected DL-Glu nanoplatelets from a recrystallization process. It has been demonstrated that the assembly of lamellar nanostructures in a radial orientation is the key for the formation of the observed Maltese-cross extinction patterns observed in many macromolecular systems, such as polymers, ${ }^{41} \mathrm{DNA}^{42}$ polysaccharides, ${ }^{43}$ and proteins. ${ }^{44}$ In our system, the Maltesecross extinction pattern weakened or even disappeared when the microspheres were air-dried. This phenomenon is similar to the weakening of the Maltese-cross extinction pattern in bovine insulin, where the pattern could not be regained upon drying and rehydration. ${ }^{43}$ The dehydration of our microspheres suggests a permanent deformation and shrinkage of microspheres.

\section{CONCLUSION}

Our results allow the conclusion that the precipitation of charged organic compounds bearing an opposite charge to that of a polyelectrolyte additive is a multistep crystallization process starting with a liquid-liquid phase separation. The PILP droplets further coalesce to micrometer sized droplets until the nucleation of nanoplatelets occurs within each PILP droplet followed by a radial nanoplatelet organization. The formation of D- or L-Glu nanoplatelets is controlled by face selective adsorption of PEI, mainly by electrostatic interaction but also by hydrogen bonds at low $\mathrm{pH}$. This mechanism shows that liquid 
precursor phases can indeed be used to form crystals that retain the shape previously adopted by the liquid precursor, since crystallization occurs within the liquid phase. The possible extension of the recipe to the pure enantiomers suggests that the observed multistep mechanism is transferable to the precipitation of other charged organic molecules with an oppositely charged polymer additive.

\section{ASSOCIATED CONTENT}

S Supporting Information. Images of the (lllll $\left.\begin{array}{lll}1 & 0 & 1\end{array}\right),\left(\begin{array}{lll}0 & 0 & 2\end{array}\right)$, $\left(\begin{array}{lll}0 & 1 & 1\end{array}\right)$, and $\left(\begin{array}{lll}1 & 1 & 0\end{array}\right)$ surfaces of $\beta$-L-Glu; figure showing the morphologies of a nanoplatelet and a single crystalline sheet; an absorbance vs time plot; and tables showing the compositions for the preparation of microspheres. This material is available free of charge via the Internet at http://pubs.acs.org.

\section{AUTHOR INFORMATION}

\section{Corresponding Author}

*Phone: +49-(0)7531-88-4063. Fax: +49-(0)7531-88-3139. E-mail: helmut.coelfen@uni-konstanz.de. Web: http://cms. uni-konstanz.de/coelfen/.

\section{Present Addresses}

"Physical Chemistry, University of Konstanz, Universitätsstrasse 10, D-78457 Konstanz, Germany.

\section{ACKNOWLEDGMENT}

This work was supported by the DFG \& NSF "Materials World Network to Study Liquid Precursor Formation and Crystallization at Interfaces: Fundamentals toward Applications. Y.J. thanks The Max Planck Institute of Colloids and Interfaces for the financial support during 2008-2010. Y.J. acknowledges Rona Pitschke, Heike Runge, and Dr. Jürgen Hartmann for SEM measurements, Dr. Nicola Pinna for providing the necessary crystal data, Adria Suarez and Felicia Svedlund for handling parts of the precipitation of L-Glu and L-His experiments, and Christelle Rosazza and Dr. Shuo Bai for the fluorescence optical microscopy measurements (data not included).

\section{REFERENCES}

(1) Aizenberg, J.; Weaver, J. C.; Thanawala, M. S.; Sundar, V. C.; Morse, D. E.; Fratzl, P. Skeleton of Euplectella sp.: Structural hierarchy from the nanoscale to the macroscale. Science 2005, 309, 275-278.

(2) Mann, S. Biomimetic Materials Chemistry; Wiley-VCH: New York, NY, 1995.

(3) Xu, A.-W.; Ma, Y.; Cölfen, H. Biomimetic mineralization J. Mater. Chem. 2007, 17, 415-449.

(4) Cölfen, H.; Antonietti, M. Mesocrystals and Nonclassical Crystallization; John Wiley \& Sons Ltd: Hoboken, NJ, 2008.

(5) Horn, D.; Rieger, J. Organic nanoparticles in the aqueous phase -theory, experiment, and use. Angew. Chem., Int. Ed. 2001, 40, 4331-4361.

(6) Kasai, H.; Nalwa, H. S.; Oikawa, H.; Okada, S.; Matsuda, H.; Minami, N.; Kakuta, A.; Ono, K.; Mukoh, A.; Nakanishi, H. A Novel Preparation Method of Organic Microcrystals. Jpn. J. Appl. Phys., Part 2: Lett. 1992, 31, L1132-L1134.

(7) Fu, H. B.; Yao, J. N. Size effects on the optical properties of organic nanoparticles. J. Am. Chem. Soc. 2001, 123, 1434-1439.

(8) Taden, A.; Landfester, K.; Antonietti, M. Crystallization of dyes by directed aggregation of colloidal intermediates: A model case. Langmuir 2004, 20, 957-961.
(9) Lee, S. J.; Hupp, J. T.; Nguyen, S. T. Growth of narrowly dispersed porphyrin nanowires and their hierarchical assembly into macroscopic columns. J. Am. Chem. Soc. 2008, 130, 9632-9633.

(10) Abyan, M.; Bertorelle, F.; Fery-Forgues, S. Use of linear polymers to control the preparation of luminescent organic microcrystals. Langmuir 2005, 21, 6030-6037.

(11) Wohlrab, S.; Cölfen, H.; Antonietti, M. Crystalline, porous microspheres made from amino acids by using polymer-induced liquid precursor phases. Angew. Chem., Int. Ed. 2005, 44, 4087-4092.

(12) Zhang, T. K.; Zhu, J. H.; Yao, H. B.; Yu, S. H. Novel fluorescein hierarchical structures fabricated by recrystallization under control of polyelectrolytes. Cryst. Growth Des. 2007, 7, 2419-2428.

(13) Bertorelle, F.; Lavabre, D.; Fery-Forgues, S. Dendrimer-tuned formation of luminescent organic microcrystals. J. Am. Chem. Soc. 2003, $125,6244-6253$.

(14) Ma, Y. R.; Börner, H. G.; Hartmann, J.; Cölfen, H. Synthesis of DL-alanine hollow tubes and core-shell mesostructures. Chem.-Eur. J. 2006, 12, 7882-7888.

(15) Ma, Y. R.; Mehltretter, G.; Plüg, C.; Rademacher, N.; Schmidt, M. U.; Cölfen, H. PY181 Pigment Microspheres of Nanoplates Synthesized via Polymer-Induced Liquid Precursors. Adv. Funct. Mater. 2009, 19, 2095-2101.

(16) Wohlrab, S.; Pinna, N.; Antonietti, M.; Cölfen, H. Polymerinduced alignment of DL-alanine nanocrystals to crystalline mesostructures. Chem.-Eur. J. 2005, 11, 2903-2913.

(17) Huang, M.; Schilde, U.; Kumke, M.; Antonietti, M.; Cölfen, H. Polymer-Induced Self-Assembly of Small Organic Molecules into Ultralong Microbelts with Electronic Conductivity. J. Am. Chem. Soc. 2010, 132, 3700-3707.

(18) Lindfors, L.; Skantze, P.; Skantze, U.; Rasmusson, M.; Zackrisson, A.; Olsson, U. Amorphous drug nanosuspensions. 1. Inhibition of Ostwald ripening. Langmuir 2006, 22, 906-910.

(19) Lindfors, L.; Forssen, S.; Skantze, P.; Skantze, U.; Zackrisson, A.; Olsson, U. Amorphous drug nanosuspensions. 2. Experimental determination of bulk monomer concentrations. Langmuir 2006, 22, 911-916.

(20) Lindfors, L.; Skantze, P.; Skantze, U.; Westergren, J.; Olsson, U. Amorphous drug nanosuspensions. 3. Particle dissolution and crystal growth. Langmuir 2007, 23, 9866-9874.

(21) Zhang, H. F.; Wang, D.; Butler, R.; Campbell, N. L.; Long, J.; Tan, B. E.; Duncalf, D. J.; Foster, A. J.; Hopkinson, A.; Taylor, D.; Angus, D.; Cooper, A. I.; Rannard, S. P. Formation and enhanced biocidal activity of water-dispersable organic nanoparticles. Nat. Nanotechnol. 2008, 3, 506-511.

(22) Cölfen, H.; Antonietti, M. Mesocrystals: Inorganic superstructures made by highly parallel crystallization and controlled alignment. Angew. Chem., Int. Ed. 2005, 44, 5576-5591.

(23) Cölfen, H.; Mann, S. Higher-order organization by mesoscale self-assembly and transformation of hybrid nanostructures. Angew. Chem., Int. Ed. 2003, 42, 2350-2365.

(24) Imai, H. Self-organized formation of hierarchical structures. Biomineralization I: Crystallization and Self-Organization Process; Springer-Verlag Berlin: Berlin, 2007; Vol. 270, pp 43-72.

(25) Gower, L. A.; Tirrell, D. A. Calcium carbonate films and helices grown in solutions of poly(aspartate). J. Cryst. Growth 1998, 191, 153-160.

(26) Gower, L. B. Biomimetic Model Systems for Investigating the Amorphous Precursor Pathway and Its Role in Biomineralization. Chem. Rev. 2008, 108, 4551-4627.

(27) Gower, L. B.; Odom, D. J. Deposition of calcium carbonate films by a polymer-induced liquid-precursor (PILP) process. J. Cryst. Growth 2000, 210, 719-734.

(28) Ma, Y. R.; Cölfen, H.; Antonietti, M. Morphosynthesis of alanine mesocrystals by $\mathrm{pH}$ control. J. Phys. Chem. B 2006, 110 10822-10828.

(29) Dunn, M. S.; Stoddard, M. P. Crystalline Anhydrous and Monohydrated DL-Glutamic Acid. J. Biol. Chem. 1937, 121, 521-529.

(30) Jiang, Y.; Gower, L. B.; Volkmer, D.; Cölfen, H. The Existence Range of a Polymer-Induced Liquid Precursor Phase to DL-Glutamic Acid Crystals. Manuscript in preparation. 
(31) Homeijer, S. J.; Olszta, M. J.; Barrett, R. A.; Gower, L. B. Growth of nanofibrous barium carbonate on calcium carbonate seeds J. Cryst. Growth 2008, 310, 2938-2945.

(32) Jee, S. S.; Thula, T. T.; Gower, L. B. Development of bone-like composites via the polymer-induced liquid-precursor (PILP) process. Part 1: Influence of polymer molecular weight. Acta Biomater. 2010, 6, 3676-3686.

(33) Hirokawa, S. A New Modification of L-Glutamic Acid and Its Crystal Structure. Acta Crystallogr. 1955, 8, 637-641.

(34) Towler, C. S.; Davey, R. J.; Lancaster, R. W.; Price, C. J. Impact of Molecular Speciation on Crystal Nucleation in Polymorphic Systems: The Conundrum of Gamma Glycine and Molecular "Self Poisoning" J. Am. Chem. Soc. 2004, 126, 13347-13353.

(35) ten Wolde, P. R.; Frenkel, D. Enhancement of protein crystal nucleation by critical density fluctuations. Science 1997, 277, 1975-1978.

(36) Galkin, O.; Vekilov, P. G. Control of protein crystal nucleation around the metastable liquid-liquid phase boundary. Proc. Natl. Acad. Sci. U.S.A. 2000, 97, 6277-6281.

(37) Rieger, J.; Frechen, T.; Cox, G.; Heckmann, W.; Schmidt, C.; Thieme, J. Precursor structures in the crystallization/precipitation processes of $\mathrm{CaCO}_{3}$ and control of particle formation by polyelectrolytes. Faraday Discuss. 2007, 136, 265-277.

(38) Dai, L.; Douglas, E. P.; Gower, L. B. Compositional Analysis of a Polymer-Induced Liquid-Precursor (PILP) Amorphous $\mathrm{CaCO}_{3}$ Phase. J. Non-Cryst. Solids 2008, 354, 1845-1854.

(39) Talanquer, V.; Oxtoby, D. W. Crystal nucleation in the presence of a metastable critical point. J. Chem. Phys. 1998, 109, 223-227.

(40) Lutsko, J. F.; Nicolis, G. Theoretical evidence for a dense fluid precursor to crystallization. Phys. Rev. Lett. 2006, 96, 046102/1-046102/4.

(41) Weber, C. H. M.; Chiche, A.; Krausch, G.; Rosenfeldt, S.; Ballauff, M.; Harnau, L.; Gottker-Schnetmann, I.; Tong, Q.; Mecking, S. Single lamella nanoparticles of polyethylene. Nano Lett. 2007, 7, 2024-2029.

(42) Rill, R. L. Liquid-Crystalline Phases in Concentrated AqueousSolutions of $\mathrm{Na}^{+}$DNA. Proc. Natl. Acad. Sci. U.S.A. 1986, 83 (2), 342-346.

(43) Kobayashi, S.; Hobson, L. J.; Sakamoto, J.; Kimura, S.; Sugiyama, J.; Imai, T.; Itoh, T. Formation and structure of artificial cellulose spherulites via enzymatic polymerization. Biomacromolecules 2000 1 (2), 168-173.

(44) Krebs, M. R. H.; MacPhee, C. E.; Miller, A. F.; Dunlop, L. E.; Dobson, C. M.; Donald, A. M. The formation of spherulites by amyloid fibrils of bovine insulin. Proc. Natl. Acad. Sci. U.S.A. 2004, 101 (40), 14420-14424. 